Environmental Change

Elsevier Editorial System(tm) for Global

Manuscript Draft

Manuscript Number: GEC-D-14-00653R3

Title: Social equity and the probability of success of biodiversity conservation

Article Type: Research paper

Keywords: Biodiversity; benefits; conservation planning; costs; equity; triple bottom line

Corresponding Author: Dr. Madeleine C McKinnon, PhD

Corresponding Author's Institution: Conservation International

First Author: Carissa Joy Klein

Order of Authors: Carissa Joy Klein; Madeleine C McKinnon, PhD; Rebecca T Wright, MS; Hugh P Possingham, PhD; Benjamin S Halpern, PhD

Manuscript Region of Origin: Australasia

Abstract: Conservation actions generally benefit some groups more than others, and this inequity is thought to affect the probability of achieving conservation objectives. This has led to the common assumption that triple bottom line solutions -- those that are effective, efficient, and equitable -- are best and most likely to achieve each individual objective. Although this may be true, it has been little tested, and importantly lacks a conceptual foundation for understanding, predicting and evaluating how equity affects conservation outcomes. We describe types of equity relevant to conservation and explore how they may affect the probability of successfully achieving conservation outcomes.

Depending on the equity type and context, the relationship between equity and conservation success varies. We find that the best conservation outcome is often achieved without perfect equity; highlighting the risk of ignoring the relationship between equity and success. We offer a conceptual foundation for better addressing this important issue in future research and application. 
2 September 2015

DearEditors,

Re: Submission to Global Environmental Change

We are pleased to share a revised manuscript that addresses minor edits from two reviewers.

Here we tackle this issue within the realm of conservation science by developing and evaluating a formal conceptual foundation for assessing social equity. In particular, we highlight several key lessons and guidelines about how best to address the issue of equity in conservation planning:

- Equity is an increasingly important issue to address in conservation, yet a poorly articulated concept in most of the literature. We developed a conceptual foundation for understanding and evaluating equity within conservation that will help make this science and its application much more rigorous.

- In most cases there is a tradeoff between achieving conservation outcomes and producing equitable solutions - sometimes a strong tradeoff. We offer a formal way of calculating and addressing this tradeoff.

- Triple-bottom line solutions - those that achieve conservation outcomes effectively, efficiently, and equitably - may be quite rare.Acknowledging (and further testing) this result could profoundly change the nature of conservation actions.

Formal evaluation of equity in conservation has only just begun. Our work poses as many questions as it tries to resolve. We anticipate it serving a foundational role in guiding future research addressing this globally important management topic.

If additional information is needed, please do not hesitate to contact me.

Yours sincerely, on behalf of all co-authors,

Dr Carissa Klein

Cover Letter

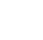

.

.

\begin{abstract}
We are grateful for their further refinements. We have attached a separate detailed response to
reviewers.
For a long time it has been recognized that conservation actions that disproportionately
impact the disenfranchised few - termed environmental injustice in the resource management
literature - are both morally wrong and less likely to achieve ultimate desired outcomes. The
interest in these topics has recently grown dramatically with the heightened attention given to global
inequity across many aspects of society, including wealth distribution, climate change impacts, and
others. What has been missing from this research and debate is a more complete assessment of how
equity in general, across the entire spectrum of equity that ranges from severe injustice to perfect
equity, affects the probability of success in achieving the desired environmental management
outcome. We are grateful for their further refinements. We have attached a separate detailed response to
reviewers.
For a long time it has been recognized that conservation actions that disproportionately
impact the disenfranchised few -termed environmental injustice in the resource management
literature - are both morally wrong and less likely to achieve ultimate desired outcomes. The
interest in these topics has recently grown dramatically with the heightened attention given to globa
inequity across many aspects of society, including wealth distribution, climate change impacts, and
others. What has been missing from this research and debate is a more complete assessment of how
equity in general, across the entire spectrum of equity that ranges from severe injustice to perfect
equity, affects the probability of success in achieving the desired environmental management
outcome. We are grateful for their further refinements. We have attached a separate detailed response to
reviewers.
For a long time it has been recognized that conservation actions that disproportionately
impact the disenfranchised few -termed environmental injustice in the resource management
literature - are both morally wrong and less likely to achieve ultimate desired outcomes. The
interest in these topics has recently grown dramatically with the heightened attention given to globa
inequity across many aspects of society, including wealth distribution, climate change impacts, and
others. What has been missing from this research and debate is a more complete assessment of how
equity in general, across the entire spectrum of equity that ranges from severe injustice to perfect
equity, affects the probability of success in achieving the desired environmental management
outcome. We are grateful for their further refinements. We have attached a separate detailed response to
reviewers.
For a long time it has been recognized that conservation actions that disproportionately
impact the disenfranchised few -termed environmental injustice in the resource management
literature - are both morally wrong and less likely to achieve ultimate desired outcomes. The
interest in these topics has recently grown dramatically with the heightened attention given to globa
inequity across many aspects of society, including wealth distribution, climate change impacts, and
others. What has been missing from this research and debate is a more complete assessment of how
equity in general, across the entire spectrum of equity that ranges from severe injustice to perfect
equity, affects the probability of success in achieving the desired environmental management
outcome. We are grateful for their further refinements. We have attached a separate detailed response to
reviewers.
For a long time it has been recognized that conservation actions that disproportionately
impact the disenfranchised few -termed environmental injustice in the resource management
literature - are both morally wrong and less likely to achieve ultimate desired outcomes. The
interest in these topics has recently grown dramatically with the heightened attention given to globa
inequity across many aspects of society, including wealth distribution, climate change impacts, and
others. What has been missing from this research and debate is a more complete assessment of how
equity in general, across the entire spectrum of equity that ranges from severe injustice to perfect
equity, affects the probability of success in achieving the desired environmental management
outcome. We are grateful for their further refinements. We have attached a separate detailed response to
reviewers.
For a long time it has been recognized that conservation actions that disproportionately
impact the disenfranchised few -termed environmental injustice in the resource management
literature - are both morally wrong and less likely to achieve ultimate desired outcomes. The
interest in these topics has recently grown dramatically with the heightened attention given to global
inequity across many aspects of society, including wealth distribution, climate change impacts, and
others. What has been missing from this research and debate is a more complete assessment of how
equity in general, across the entire spectrum of equity that ranges from severe injustice to perfect
equity, affects the probability of success in achieving the desired environmental management
outcome. We are grateful for their further refinements. We have attached a separate detailed response to
reviewers.
For a long time it has been recognized that conservation actions that disproportionately
impact the disenfranchised few -termed environmental injustice in the resource management
literature - are both morally wrong and less likely to achieve ultimate desired outcomes. The
interest in these topics has recently grown dramatically with the heightened attention given to global
inequity across many aspects of society, including wealth distribution, climate change impacts, and
others. What has been missing from this research and debate is a more complete assessment of how
equity in general, across the entire spectrum of equity that ranges from severe injustice to perfect
equity, affects the probability of success in achieving the desired environmental management
outcome. We are grateful for their further refinements. We have attached a separate detailed response to
reviewers.
For a long time it has been recognized that conservation actions that disproportionately
impact the disenfranchised few -termed environmental injustice in the resource management
literature - are both morally wrong and less likely to achieve ultimate desired outcomes. The
interest in these topics has recently grown dramatically with the heightened attention given to global
inequity across many aspects of society, including wealth distribution, climate change impacts, and
others. What has been missing from this research and debate is a more complete assessment of how
equity in general, across the entire spectrum of equity that ranges from severe injustice to perfect
equity, affects the probability of success in achieving the desired environmental management
outcome. We are grateful for their further refinements. We have attached a separate detailed response to
reviewers.
For a long time it has been recognized that conservation actions that disproportionately
impact the disenfranchised few -termed environmental injustice in the resource management
literature - are both morally wrong and less likely to achieve ultimate desired outcomes. The
interest in these topics has recently grown dramatically with the heightened attention given to globa
inequity across many aspects of society, including wealth distribution, climate change impacts, and
others. What has been missing from this research and debate is a more complete assessment of how
equity in general, across the entire spectrum of equity that ranges from severe injustice to perfect
equity, affects the probability of success in achieving the desired environmental management
outcome. We are grateful for their further refinements. We have attached a separate detailed response to
reviewers.
For a long time it has been recognized that conservation actions that disproportionately
impact the disenfranchised few -termed environmental injustice in the resource management
literature - are both morally wrong and less likely to achieve ultimate desired outcomes. The
interest in these topics has recently grown dramatically with the heightened attention given to globa
inequity across many aspects of society, including wealth distribution, climate change impacts, and
others. What has been missing from this research and debate is a more complete assessment of how
equity in general, across the entire spectrum of equity that ranges from severe injustice to perfect
equity, affects the probability of success in achieving the desired environmental management
outcome. We are grateful for their further refinements. We have attached a separate detailed response to
reviewers.
For a long time it has been recognized that conservation actions that disproportionately
impact the disenfranchised few -termed environmental injustice in the resource management
literature - are both morally wrong and less likely to achieve ultimate desired outcomes. The
interest in these topics has recently grown dramatically with the heightened attention given to globa
inequity across many aspects of society, including wealth distribution, climate change impacts, and
others. What has been missing from this research and debate is a more complete assessment of how
equity in general, across the entire spectrum of equity that ranges from severe injustice to perfect
equity, affects the probability of success in achieving the desired environmental management
outcome.
\end{abstract}

Yours sincerely, on behalf of all co-authors,

.

.




\section{Social equity and the probability of success of biodiversity}

\section{conservation}

Carissa Klein $^{1 *}$, Madeleine C. McKinnon, ${ }^{3}$, Becky Twohey Wright ${ }^{4}$, Hugh P. Possingham ${ }^{3,5}$, Benjamin S. Halpern $5,6,7$

1 - Centre for Biodiversity and Conservation Science, School of Geography Planning and Environmental Management, University of Queensland, St. Lucia, Queensland, 4072 Australia. +61401582606 (phone). c.klein@uq.edu.au

2 - Conservation International, Betty \& Gordon Moore Center for Science \& Oceans, Arlington, VA 22202 USA. 310-500-0081. mbottrill@ conservation.org

3 - Centre for Biodiversity and Conservation Science, School of Biological Sciences, University of Queensland, St. Lucia, Queensland, 4072 Australia.+61401582606, h.possingham@uq.edu.au

4 - Interdepartmental Graduate Program in Marine Science, University of California, Santa Barbara, California, USA. 805-450-6537. rebecca.wright@lifesci.ucsb.edu

5 - Imperial College London, Silwood Park Campus, Buckhurst Road, Ascot SL57PY, UK

6 - The Bren School of Environmental Science and Management, University of California, Santa Barbara, USA. 805-893-2862. halpern@ bren.ucsb.edu.

7 - National Center for Ecological Analysis \& Synthesis, Santa Barbara, CA 93101, USA

*Corresponding author 


\section{Acknowledgements}

This work was largely funded by an Australian Research Council Discovery Grant (DP140100733) to CJK and BSH and partly by the ARC Centre of Excellence for Environmental

Decisions. We thank Morena Mills for her feedback and comments from two anonymous reviewers that greatly improved this manuscript. 
Ms. Ref. No.: GEC-D-14-00653

Title: Social equity and the probability of success of biodiversity conservation

Global Environmental Change

September 1, 2015

Dear Editors,

We are pleased that our manuscript has been accepted following further revision. We have slightly revised the final manuscript to address the two minorcomments from the reviewers. Below we detail our responses to each comment, with the original comment in bold and our response in regular font.

\section{Reviewer \#1:}

The final minor amendment I would recommend relates to their response comment that they have identified whether they are discussing input or output equity in each examples in Section 3.

Response: We have clarified in the subsections (3.1-3.4) whether the examples described relate to input or output equity. (Edits are within lines 179-182; 193; and 235).

\section{Reviewer \#2:}

There is one point that I think they have not got yet. It does not preclude publication - for as the authors observe, many people do not get it But they could draw attention to this more explicitly, the text they wrote in their response to me would suffice.

Response: We have added further justification for our belief that different values of equity might be comparable. See Line 311:

"Not all perceived values of conservation (associated with either costs or benefits) will be tangible or easily quantifiable; yet assessing their relative importance has merit. Any type of equity in principle could be measured subjectively on a unitless scale of low to high. Formalization of problems that involve values can be an anathema to some, but the benefits of explicating integrating these issues into formal conservation planning are greater than ignoring perceived values altogether." 


\section{Highlights:}

- Social equity, economic efficiency and environmental effectiveness are often sought

- Social equity can be necessary for success, but can compromise other goals

- We enhance our understanding of the social equity-conservation success relationship

- The best conservation outcome is often achieved without perfect social equity 
3 Running Title: Social equity and conservation success 


\section{Abstract}

5 Conservation actions generally benefit some groups more than others, and this inequity is

6 thought to affect the probability of achieving conservation objectives. This has led to the

7 common assumption that triple bottom line solutions -- those that are effective, efficient, and

8 equitable -- are best and most likely to achieve each individual objective. Although this may be

9 true, it has been little tested, and importantly lacks a conceptual foundation for understanding,

10 predicting and evaluating how equity affects conservation outcomes. We describe types of equity

11 relevant to conservation and explore how they may affect the probability of successfully

12 achieving conservation outcomes. Depending on the equity type and context, the relationship

13 between equity and conservation success varies. We find that the best conservation outcome is

14 often achieved without perfect equity; highlighting the risk of ignoring the relationship between

15 equity and success. We offer a conceptual foundation for better addressing this important issue in

16 future research and application.

\section{Keywords}

18 Biodiversity, benefits, conservation planning, costs, environment, equity, triple bottom line 


\section{Introduction}

21 Social equity - the equitable distribution of costs or benefits between individuals or groups of

22 people - is a highly sought after ideal in many aspects of society. Whether related to education,

23 employment, or healthcare, equitable outcomes or opportunities can influence the creation,

24 durability, and success of local, national, and international policies (Solar and Irwin 2007). The

25 conservation of biodiversity is no exception (Halpern et al. 2013). In contrast to health and

26 education, however, relatively little work has been done to understand how, and in what cases,

27 explicit consideration of equity influences effectiveness of a conservation plan or policy

28 (henceforth 'conservation intervention', which can include, but is not limited to: protected area

29 plans/policies, payments for ecosystem services plans/policies, etc.). Here we aim to enhance

30 our understanding of the relationship between different types of social equity and success in

31 biodiversity conservation interventions, with the goal of improving conservation outcomes. A

32 rich body of literature exists on measuring the effectiveness of conservation interventions, and

33 understanding factors affecting the probability of their success (Bottrill and Pressey 2012;

34 Ferraro and Hanauer 2014; Mascia et al. 2014). Success in conservation is broadly defined by

35 achievement of stated goals, which vary according to different values and beliefs. For example,

36 a successful protected area plan could be measured by ecological representation, biodiversity

37 persistence, or economic impact (Parrish et al. 2003; Klein et al. 2010), whereas a successful

conservation policy could be measured by improved strength of legislation governing the use of

39 natural resources (Gleason et al. 2010) or community support (Russ and Alcala 1999). Other

40

conservation outcomes might be measured by changes in social, institutional or human capital

41 (Bottrill and Pressey 2012; Ban et al. 2013). Ultimately, the success of conservation

42 interventions is often evaluated on the basis of conservation benefit, social equity, and economic 
43 return, the three components to triple bottom line conservation outcomes (Halpern et al. 2013).

44 Yet the feasibility of achieving such triple bottom line solutions, and the potential interactions

45 and tradeoffs among the three components, remains largely untested. Halpern et al. (2013) found

46 that social equity can compromise achieving efficient conservation outcomes, but highlighted the

47 importance of further research focused on exploring how the relationship between social equity

48 and conservation success might influence these trade-offs, in particular with respect to the many

49 different types of equity. Here, we explore this relationship to provide insight to outstanding

50 questions in conservation, including: Is probability of conservation success actually optimized

51 when all three components are maximized? Or, does conservation success require approaches

52 that deviate from the triple bottom line?

53 Equity is increasingly recognized as a component of conservation success (Ban et al. 2013;

54 Campese et al. 2009). However, there are multiple types of equity (Figure 1), and being clear

55 about what type of equity is important and being measured is critical for understanding the

56 relationship between conservation success and equity. Equity concerns can arise from both

57 internal factors (e.g., composition of the project team), which tend to be within the control of the

58 planning team, and external contextual factors (e.g., social, geographic or economic conditions

59 of the planning region), which are generally beyond the control of the project. For example, the

60 design of a stakeholder engagement strategy might consider equal participation of different

61 groups in a consultation process designed to ensure representation from all affected stakeholders,

62 an internal factor. Alternatively, the variation and spatial distribution of existing income levels in

63 the planning region might determine which populations or communities are affected by

64 restrictions on resource use recommended by a conservation plan, an external contextual factor.

65 While external factors can rarely be controlled, understanding, anticipating and managing their 
66 influence on the design and implementation of a conservation intervention is likely to increase its

67 probability of success (Berkes 2004; Solar and Irwin 2007). Internal factors can be inputs into,

68 and/or outcomes of, a conservation intervention, and can influence its success (Figure 1). We

69 believe that consideration of different types of equity improves the chance of achieving

70 conservation success.

71 The focus of this manuscript is on how social equity, one of many potential conservation

72 objectives and factors affecting conservation success, influences the probability a conservation

73 intervention succeeds in meeting its stated goal. We acknowledge that cases exist where equity

74 plays little to no role in conservation interventions and their success, for example when

75 governments impose protected areas despite local protests (Brockington 2004), but our emphasis

76 here is on cases where equity matters. We identify different types of input and outcome equity

77 and discuss their possible relationships with conservation success. Finally, we simulate how

78 understanding these relationships can help us evaluate the feasibility of triple bottom line

79 solutions, where social equity, environmental benefit, and economic return are maximized.

\section{$80 \quad 2$ Social equity in conservation}

81 A complex collection of social structures, economic systems, and policy frameworks determine

82 the relevance of equity to conservation outcomes, and thus conservation success. These social

83 determinants of conservation equity reflect the distribution of wealth, power, and access to

84 resources within a society, and can in turn have different consequences for different types of

85 conservation equity. We identified many types of conservation equity, and divided them into two

86 main categories, input and outcome, that influence conservation success (Figure 1), all of which

87 can be influenced by socioeconomic and political context (described below in section 2.1). 
88 Several types of equity can be either input or outcome equity, or both, depending on the decision

89 process and goals of the conservation action. The primary distinction is whether the type of

90 equity is a dimension of the social context that influences the process of making a conservation

91 decision, i.e., input equity, or is something affected by the conservation action, i.e., outcome

92 equity. As such, potential metrics of these types of equity are often the same (Fig. 1b), but how

93 they are used and interpreted will differ. Differences between input and outcome equity are

94 further explained and illustrated below.

\section{$95 \quad 2.1$ Socioeconomic and political context}

96 Context variables encompass a broad set of structural, cultural, and functional aspects of a social

97 system that exert a powerful formative influence on patterns of social stratification and, thus,

98 influence conservation equity (Ostrom 1990; Solar and Irwin 2007). Fully characterizing all

99 components of context is beyond the scope of this paper. Context determinants are often beyond

100 the control of a conservation intervention, representing external factors influencing conservation

101 success, except when the goal of the intervention is to change existing governance structures or

102 policies. We highlight context here because it influences equity and thus affects conservation

103 success. Examples of determinants related to context affecting conservation success include

104 governance, cultural and societal values, and social/economic/public policies (Figure 1).

\section{$105 \quad 2.2$ Input Equity}

106 The socioeconomic and political context within a planning region gives rise to different forms of

107 social position and hierarchy within groups of individuals. Populations can be stratified by

108 socioeconomic position according to education, occupation, gender/age, race/ethnicity, 
generational, financial status and other factors (Figure 1). In some cases, these different groups participate in the conservation intervention through a participatory process, and help guide decisions about what and where to protect; we classify this as a form of input equity. For example, a decision process that includes only men or only wealthy people would be inequitable for those two types of input equity, and this may ultimately affect the ability to achieve the conservation outcome. In particular, the existence and equitability of the participatory process can directly influence conservation success by slowing or stopping the decision process, where in extreme cases the lack of a participatory process is responsible for failure of the intervention (Gleason et al. 2010). In other cases, the participatory process can influence the outcome of the intervention (e.g., the size or location or regulations of a protected area plan), which can in turn indirectly influence conservation success.

\subsection{Outcome Equity}

Outcome equity refers to the distribution of costs and benefits of the final outcome of the conservation intervention (e.g., a protected area plan) to different socio-economic groups and/or across space (Figure 1). For example, a protected area plan can disproportionately impact different socioeconomic groups, such as different industry sectors (Adams et al. 2010; occupation equity), by restricting access to a natural resource (access or spatial equity). In many cases input equity can influence outcome equity, as those involved in the decision process may design a conservation intervention that favors themselves and thus leads to outcome inequity, often for the same type of equity (e.g., if men dominate the decision process, they may produce outcomes that produce greater benefits for men). Outcome equity can be independent of input equity when conservation interventions do not involve a participatory process. 


\section{Equity and probability of conservation success}

132 Once the types of equity relevant to a conservation intervention have been identified,

133 conservation success requires understanding how these types of equity affect the probability of

134 success. Increased social equity is often assumed to improve the probability of conservation

135 success (Brown 2002; Halpern et al. 2013). In some cases, this assumption may be true; for

136 example, in the implementation of locally managed marine areas, where self enforcement of new

137 regulations is more likely to occur when local people perceive the regulations as equitable

138 (Hatcher et al. 2000). However, it is also likely that conservation will fail if vocal or powerful

139 individuals or groups are not satisfied with the outcome, in other words, if the outcomes of

140 conservation planning and actions do not match the (often inequitable) local context. The

141 relationship between equity and probability of conservation success is presumed to be positive

142 (Brown 2002) yet is poorly understood, and further complicated when values and perceptions

143 among and between different groups are taken into account too (Ravallion 2014; Figure 2).

144 Recognizing the difference between absolute, relative and perceived is critical for objective

145 setting and evaluation of intervention outcomes. Absolute equity refers to every participant

146 experiencing the same, or equal, outcome. For example, regardless of size, every boat is allowed

147 to catch the same number of fish (Figure 2). Relative equity refers to participants experiencing a

148 proportional outcome related to a stated variable, e.g., boats receiving fish catch in proportion to

149 their boat size as compared to other boats. Perceived equity is how those involved in the process

150 perceive of their allotted outcome compared others, e.g., the size of fish catch relative to other

151 fishers. 
152 Here, we describe four general relationships that have been observed between equity and 153 probability of conservation success $(P(x)$; Figure 3): A) Linear, where $P(x)$ increases

154 proportionally with increasing equity; B) Asymptotic, where $P(x)$ increases rapidly with initial 155 increases in equity and then plateaus; C) Humped, where $P(x)$ rises initially and then drops off 156 with higher levels of equity, and D) Sigmoidal, where $P(x)$ responds slowly at first to increases 157 in equity and then rises quickly. For nonlinear shapes, the location of inflection points (i.e., 158 change in slope) is likely connected to a contextual determinant, such as governance or cultural 159 value. For each relationship, we describe it in the terms of individual types of equity and support 160 it using empirical evidence, where possible. These four relationships are hypotheses; their

161 frequency of occurrence and impact on overall conservation outcomes are still to be fully tested. 162 We hope the conceptual foundation described here helps make such testing more rigorous. For 163 any equity type, its relationship with conservation success will likely vary from case to case 164 depending on how equity is considered in the process (as an input or an outcome), how equity is 165 measured (as quantitative or qualitative values, e.g., dollars versus participation effort), and how 166 equity is defined (as absolute, relative or perceived) (McClanahan et al. 2008) (Figure 2).

167 3.1. Linear

168 Occupational and spatial equity are two of several types of equity that may relate linearly with 169 conservation success (Figure 3a). For example, it seems reasonable to expect conservation plans 170 that produce more equitable relative impact to each key occupational sector, would be more 171 successful. In California, the Marine Life Protection Act Initiative is an example of a successful 172 conservation plan that made considerable effort to equitably impact commercial fishery sectors 173 in each major region (Klein et al. 2010; White et al. 2013). 
174 With spatial equity, a linear relationship between equity and conservation success has been

175 observed with a type of spatial fisheries management, Territorial User Rights in Fisheries

176 (TURFs), which allow individuals or a set group of people to fish in a particular area. TURFs

177 have demonstrated increasingly positive outcomes with increasing levels of both input and

178 output equity. For example, Chilean TURF cooperatives allocate effort temporally and spatially

179 via a pooling scheme (input equity), to equalize the work burden and spread effort in a more

180 efficient manner (Cancino et al. 2007), and this program has successfully met conservation goals

181 (by not exceeding the total allowable catch) and social goals (by equally distributing the

182 transaction costs and benefits of the TURF) - an example of output equity.

\section{$183 \quad 3.2$ Asymptotic}

184 Financial and participation equity are two of several types of equity that could relate to

185 conservation success asymptotically (Figure 3b), where conservation success increases with

186 increasing levels of equity to a point, after which equity does not influence success. With

187 financial equity, conservation success is assumed to increase with increasing financial equity

188 (i.e., distribution between groups regardless of financial status or profitability). However, in

189 some cases conservation success is likely to peak, and remain constant, when more powerful or

190 vocal stakeholders receive the greatest benefit. For example, when the Great Barrier Reef was

191 rezoned, the government provided monetary compensation to commercial fishermen but not to

192 other, more profitable industries (Macintosh et al. 2010). As fishermen were the most vocal

193 stakeholder group, allocation of additional money to other groups, an example of output equity,

194 may not have impacted conservation success, resulting in an asymptotic relationship. 
195 Similarly to financial equity, the probability of success of conservation interventions could

196 increase, to a point, with increasing participation from stakeholder groups (participation equity).

197 An example of how stakeholder participation can lead to successful conservation was

198 demonstrated using data from 84 forest management cases around the world (Persha et al. 2011);

199 whereas, lack of stakeholder participation lead to an unsuccessful conservation was shown in the

200 first attempt to implement the California's Marine Life Protection Act (Gleason et al. 2010).

201 Similarly, in Alaska where all federal fisheries are managed by annual catch limits and some

202 type of limited access program, stakeholders and the public have several opportunities for

203 participation input during the development phase, which is recognized as critical for building

204 stakeholder acceptance of the program and balancing divergent interests (Fina 2011). However,

205 this relationship is unlikely to be linear, as conservation success likely stabilizes once the most

206 vocal or influential stakeholders are included in the process (i.e., engaging additional, less

207 influential stakeholders in the decision process might increase equity but likely have little effect

208 on conservation success).

2093.3 Humped

210 Generational, gender, social, ethnicity, and financial (described above) are types of equity that

211 could affect conservation success in a humped fashion, where the peak of the hump reflects the

212 point in which conservation success is maximized. For example, some conservation initiatives

213 favor current generations and disproportionately impose costs on future generations, indicating a

214 humped shaped relationship that peaks early to reflect the bias towards current generations

215 (Figure 3c) (Dobbs 1982). Generational equity would be difficult to achieve as a type of input

216 equity given timeframes involved in most decision processes. In many societies, conservation 
217 success is generally assumed to increase linearly with increased gender equity inputs and outputs

218 (Agarwal 2009; Figure 3a). However, conservation success probably peaks at a point that

219 matches the power structure of a society. In many places, decisions are often made by, or favor, a

220 single gender (Martin and Lemon 2001; Agarwal 2009; Tsikata and Golah 2010), thus

221 conservation success would peak at the point that reflects this power structure. Other types of

222 equity, in particular social class and ethnicity, often reflect different power and influence among

223 groups within regions. In community forestry programs in Nepal, while socially dominant

224 (higher caste) individuals make management decisions affecting all groups, lower caste social

225 classes harvest a majority of the forest resources, and therefore conservation success is unlikely

226 to occur until they are involved, even if at a minimal level. Yet, higher caste groups might not

227 tolerate a substantial redistribution of decision-making rights among other social classes

228 reflecting a humped relationship (Nightingale 2002).

2293.4 Sigmoidal

230 Types of equity that potentially have an asymptotic relationship to conservation success would

231 exhibit a sigmoidal relationship in cases where some minimum threshold level of equity exists

232 that is needed to achieve success. For example, in fisheries management based on individual

233 transferable quotas, each fisher (or fisher group) is allowed a 'catch share' (i.e., access equity)

234 that can be used, sold, or leased. This form of regulation is only likely to be successful if some

235 minimum threshold of output equity is achieved, or in other words, fishermen are not entirely

236 excluded from the process. If access equity increases, more people are given access to a smaller

237 portion of the fishery, assuming a total allowable catch has been set and remains constant, and

238 thus individual catch would decrease. In this case, probability of success likely plateaus at some 
239 intermediate level of equity (sigmoidal relationship). For example, the halibut and sablefish

240 fisheries have historically supported a large number of small vessels (Fina 2011). Both set

241 individual fishing quotas (IQFs) to reflect historic fisheries access, but entry into the fishery is

242 limited. Thus, probability of success increases to a point where enough of the fishers buy into the

243 program, but probably plateaus at a point where entry (access equity) is limited and total

244 allowable catch and catch shares remain steady.

\subsection{Additional aspects of the curves}

246 Some types of equity may express different relationship curves depending on the context. For 247 example, with the catch allocation example in section 3.4, if individuals become less satisfied 248 with their shrinking allocation of catch with increasing equity, they may begin violating 249 regulations, in turn decreasing conservation success at higher levels of equity (humped shape 250 curve instead of sigmoidal). Similarly, the relationship between financial equity and conservation 251 success may be humped if groups without much power or voice receive money that could have 252 gone to groups that feel they deserve more, causing those groups to perceive the allocation as 253 inequitable and unacceptable for success.

254 A key unknown about any of the potential relationships between equity and conservation success 255 is where the curve crosses an axis (Fig. 1a, inset). It is often assumed that conservation 256 interventions will fail without some minimum level of equity (Borrini et al. 2004), such that the 257 curves would intersect the $\mathrm{x}$-axis at some value greater than zero. Yet there are other examples

258 where conservation has been successful despite highly inequitable outcomes, for example where 259 top-down management displaces local communities (Brockington 2004, de Santo et al. 2011). In 260 these cases, the curves would intersect the y-axis at a value greater than zero. 
261 Additionally, different types of equity, each with its own curve, may be relevant and important

262 within the same management plan. Such differences further challenge incorporating equity into

263 conservation planning, but can be resolved at least partially by efforts to elicit the relative

264 importance of each type of equity to stakeholder groups and then incorporate those weights into

265 formal multi-criteria decision making (Kittinger et al. 2014).

2674 Discussion

268 We need a better understanding of the relationship between equity and conservation success,

269 including when and how much social equity contributes to conservation success, to achieve

270 conservation goals. We provide a conceptual foundation for understanding how and when

271 different types of equity can influence conservation success relative to how equity is measured

272 and perceived. Understanding the nature of these interactions between equity, conservation

273 success, and economic return is fundamental for determining the feasibility of triple bottom line

274 solutions. In conservation planning, expected conservation benefit is typically calculated as the

275 product of probability of success and conservation benefit. In general, conservation benefit

276 reflects both biodiversity conservation and economic efficiency objectives, addressing two

277 pillars of the triple bottom line (Halpern et al. 2013). Here we demonstrate, in theory, how a

278 third pillar, equity, potentially affects probability of conservation success (shown in Figure 3),

279 and how this in turn interacts with the way equity can limit potential conservation benefits

280 (Figure 4). The implication of these results is that equity can either exacerbate (Fig. 4b-d) or

281 mitigate (Fig. 4a) the ability to achieve biodiversity and economic conservation objectives. In

282 most cases, the optimal conservation outcome is achieved without perfect equity. In fact, high 
283 levels of equity could severely compromise conservation outcomes (e.g. Figure 4c) if, for 284 example, existing power structures are themselves inequitable, which highlights the risk of not 285 considering the relationship between equity and probability of success.

287 We simplified the problem by considering each type of equity separately, but acknowledge that 288 complex relationships exist among specific types of equity and between context determinants 289 (Adelman and Morris 1973), and that these interactions influence the degree of success. Further, 290 we acknowledge that additional relationships are likely to exist (e.g., nonlinear shapes with 291 multiple inflection points, flat lines where equity has no bearing on conservation success), and 292 that the relationships may change through time, as people learn and adapt, and among 293 communities that have different contexts. Similarly, different groups within a planning process 294 may value different types of equity, and if those types influence the process (input equity) or 295 respond differently to the conservation intervention (outcome equity), then overall conservation 296 success could be compromised. A more indepth understanding of these relationships and 297 interactions is important and will require empirical research focused on determining or 298 evaluating specific relationships between the probability of success and equity, as well as how 299 different types of equity are valued by stakeholders within a planning process (i.e., how much 300 weight to give each one in planning decisions). Embarking on this substantial research agenda 301 requires a conceptual foundation, which is the crux of this manuscript.

303 Complicating matters further, the actual relationship between equity and conservation success 304 may differ from the perceived relationship of equity for different individuals or groups (Webb et 305 al. 2004; McClanahan et al. 2008). Perceptions of equity and conservation success reflect the 
values of those involved in, or affected by, a program or strategy, their expectations, and whether

307 goals are achieved (Axford et al. 2008). Perceptions are important as they lead people to change

308 their behavior (e.g., whether or not to comply to new regulations) and/or lead to new

309 conservation actions (Claus et al. 2010). As with absolute equity, perceptions of equity will

310 likely change through time and vary among individuals and communities, creating an additional

311 challenge for understanding the relationship between equity and conservation success. Not all

312 perceived values of conservation (associated with either costs or benefits) will be tangible or

313 easily quantifiable; yet assessing their relative importance has merit. Any type of equity in

314 principle could be measured subjectively on a unitless scale of low to high. Formalization of

315 problems that involve values can be an anathema to some, but the benefits of explicating

316 integrating these issues into formal conservation planning are greater than ignoring perceived

317 values altogether.

319 Social equity in conservation has emerged from concern for environmental justice and fairness, 320 in particularly, for those groups most affected by conservation interventions or most dependent

321 on natural resources for their livelihoods. These issues reflect two important key ethical

322 considerations. The first, which has been the primary focus of this paper, relates to how social

323 equity among and between different groups might be represented in the process or outcomes of

324 conservation planning. The second relates more specifically to how different types of equity are

325 defined, by whom and for which groups. Goals reflect the values and beliefs of those individuals

326 or groups that set them. We have suggested several key types of equity, but these are by no

327 means exhaustive or prescriptive. Rather we provide a conceptual basis for articulating types of

328 equity, the possible relationships between equity and conservation outcomes, and ways to 
329 interpret trade-offs among types of equity and between equity and conservation outcomes. Such

330 a framework has the potential to inform and support rights-based approaches to conservation. It

331 would be nearly impossible to consider all types of equity at once, thus conservation planners

332 have to make some decision as to which types of equity to consider. Similar decisions are made

333 when considering economic and ecological objectives, e.g., which actions to take to conserve

334 which species (Bottrill et al., 2008). How these decisions are made will depend on the local

335 context in which the conservation intervention occurs, but we recommend an explicit conceptual

336 framework to promote transparency and balance different perspectives.

337

338 Our conceptual foundation provides a lens through which issues of equity and conservation

339 success can be viewed and studied using empirical data. This foundation informs further

340 research required to resolve outstanding issues, including: 1) empirical evidence to document

341 and measure the frequency of occurrence and effect of different types of social equity on the

342 probability of conservation success; 2) information on whether minimum thresholds of equity are

343 required to achieve conservation success (Figure 3a); 3) data on the contribution of equity versus

344 other factors in affecting conservation success among different interventions, and potential

345 tradeoffs among these factors; 4) a systematic review to synthesize existing evidence on which

346 types of interventions, and their relative conservation success, are most influenced by which

347 types of social equity; and 5) definitions and perceptions of conservation success among and

348 across different groups and contexts. Greater knowledge of these issues will improve our

349 understanding of how and when to consider equity in conservation decisions making.

351 Multiple objectives are common in conservation, yet there is not always consensus on objectives 
352 among individuals and groups. Conservation planning can only strive to achieve the stated

353 objectives and ensure that the objectives are clear, measurable and identified through a

354 transparent and participatory process with multiple stakeholders. Governments and organizations

355 are increasingly moving away from purely biophysical approaches to biodiversity conservation

356 to more holistic approaches based on sustainable human interactions, which require integration

357 of environmental, social, and economic demands. Although substantial work has been done to

358 promote the need for addressing social factors in effective planning design and implementation

359 (Ban et al. 2013), there has been little focus on social equity and its influence on conservation

360 outcomes, despite the assumption that triple bottom line solutions are commonly held as ideal.

361 We hope our work here will help improve conservation success by shedding light on how and

362 why equity influences the probability of success, the consequences of not adequately considering

363 equity on conservation outcomes, and provide guidance on tradeoffs among social equity,

364 economic efficiency, and conservation effectiveness for conservation interventions.

\section{References}

366

367
Adams V, Pressey R, and Naidoo R. (2010). Opportunity costs: Who really pays for conservation? Biol Conserv 143: 439-48.

Adelman I and Morris C. (1973). Economic growth \& social equity in developing countries. Stanford: Stanford University Press.

Agarwal B. (2009). Gender and forest conservation: The impact of women's participation in community forest governance. Ecol Econ 68: 2785-99.

Axford JC, Hockings MT, and Carter RW. (2008). What constitutes success in Pacific island community conserved areas? Ecol Soc 13: 45-61.

Ban NC, Mills M, Tam J, et al. (2013). A social-ecological approach to conservation planning: embedding social considerations. Front Ecol Environ 11: 194-202.

Berkes F. 2004. Rethinking community-based conservation. Conserv Biol 18: 621-30. 
Borrini, Grazia, Ashish Kothari, and Gonzalo Oviedo. (2004) Indigenous and local communities and protected areas: Towards equity and enhanced conservation: Guidance on policy and practice for co-managed protected areas and community conserved areas. No. 11. IUCN, Gland, Switzerland.

Bottrill, M., Joseph, L. N., Carwardine, J., Bode, M., Cook, C., Game, E. T., Grantham, H., Kark, S., Linke, S., McDonald-Madden, E., Pressey, R. L., Walker, S., Wilson, K. A. \& Possingham, H. P. (2008). Is conservation triage just smart decision-making? Trends in Ecology \& Evolution, 23, 649-654.

Bottrill MC and Pressey RL. (2012). The effectiveness and evaluation of conservation planning. Conserv Lett 5: 407-20.

Brockington, D. (2004). Community conservation, Inequality and Injustice. Myths of Power in Protected Area Management. Conservation and Society 2 (2): 411-432

Brown K. (2002). Innovations for conservation and development. Geogr J 168: 6-17.

Cancino JP, Wilen JE, and Uchida H. (2007). TURFs and ITQs : Collective vs . individual decision making. University of Rhode Island. Mar Resour Econ 22: 391-406.

Claus C, Chan K, and Satterfield T. (2010). The roles of people in conservation. Conserv Biol all: 262-83.

De Santo, E. M., P. J. S. Jones, and A. M. M. Miller. (2011) Fortress conservation at sea: a commentary on the Chagos marine protected area. Marine Policy 35.2: 258-260.

Dobbs I.M. (1982). Discounting, intergenerational equity and the almost-anywhere dominance criterion. Futures 14: 307-12.

Ferraro, P.J and Hanauer, M.M. (2014). Quantifying causal mechanisms to determine how protected areas affect poverty through changes in ecosystem services and infrastructure. Proc Natl Acad Sci U S A 111: 4332-7.

Fina, M. (2011). Evolution of Catch Share Management: Lessons from Catch Share Management in the North Pacific, Fisheries 26(4): 164-177

Gleason M, McCreary S, Miller-Henson M, et al. (2010). Science-based and stakeholder-driven marine protected area network planning: A successful case study from north central California. Ocean Coast Manag 53: 52-68.

Halpern, B.S., Klein, C.J., Brown, C.J., et al. (2013). Achieving the triple bottom line in the face of inherent tradeoffs among social equity, economic return and conservation. Proc Natl Acad Sci doi:10.107. 
Hatcher A, Jaffry S, Thebaud O, and Bennett E. (2000). Normative andsocial influences affecting compliance with fishery regulations. Land Econ 76: 448-61.

Kittinger, John N., et al. (2014) A practical approach for putting people in ecosystem-based ocean planning." Frontiers in Ecology and the Environment 12.8: 448-456.

Klein CJ, Steinback C, Watts ME, et al. (2010). Spatial marine zoning for fisheries and conservation. Front Ecol Environ 8: 349-53.

Macintosh A, Bonyhady T, and Wilkinson D. (2010). Dealing with interests displaced by marine protected areas: A case study on the Great Barrier Reef Marine Park Structural Adjustment Package. Ocean Coast Manag 53: 581-8.

Martin A and Lemon M. (2001). Challenges for participatory institutions: The Case of Village Forest Committees in Karnataka, South India. Soc Nat Resour 14: 585-97.

Mascia MB, Pailler S, Thieme ML, et al. (2014). Commonalities and complementarities among approaches to conservation monitoring and evaluation. Biol Conserv 169: 258-67.

McClanahan TR, Cinner J, Kamukuru AT, et al. (2008). Management preferences, perceived benefits and conflicts among resource users and managers in the Mafia Island Marine Park, Tanzania. Environ Conserv 35: 340.

Nightingale AJ. (2002). Participating or just sitting in? The dynamics of gender and caste in community forestry. J For livelihood vol 2: 1.

Ostrom E. (1990). Governing the Commons: The evolution of institutions for collective action. Cambridge, United Kingdom: Cambridge University Press.

Parrish JD, Braun DP, and Unnasch RS. (2003). Are we conserving what we say we are? Measuring ecological integrity within protected areas. Bioscience 53: 851-60.

Persha L, Agrawal A, and Chhatre A. (2011). Social and ecological synergy: local rulemaking, forest livelihoods, and biodiversity conservation. Science 331: 1606-8.

Ravallion M. (2014). Income inequality in the developing world. Science 344: 851-5.

Russ GR and Alcala AC. (1999). Management histories of Sumilon and Apo Marine Reserves, Philippines, and their influence on national marine resource policy. Coral Reefs 18: 307-19.

Solar O and Irwin A. (2007). A Conceptual Framework for Action on the Social Determinants of Health.

Tsikata D and Golah P (Eds). (2010). Land tenure, gender, and globalisation: research and analysis from Africa, Asia, and Latin America. New Delhi and Ottawa: International Development Research Centre and Zubaan. 
441 Webb EL, Maliano RJ, and Siar S V. (2004). Using local user perceptions to evaluate outcomes 442 of protected area management in the Sagay Marine Reserve, Philippines. Environ Conserv 443 31: $138-48$.

444 White JW, Scholz AJ, Rassweiler A, et al. (2013). A comparison of approaches used for 445 economic analysis in marine protected area network planning in California. Ocean Coast $446 \quad$ Manag 74: 77-89.

447

448 


\section{$449 \quad$ Figures}

450

$451 \quad$ Figure 1.

(a) Absolute equity
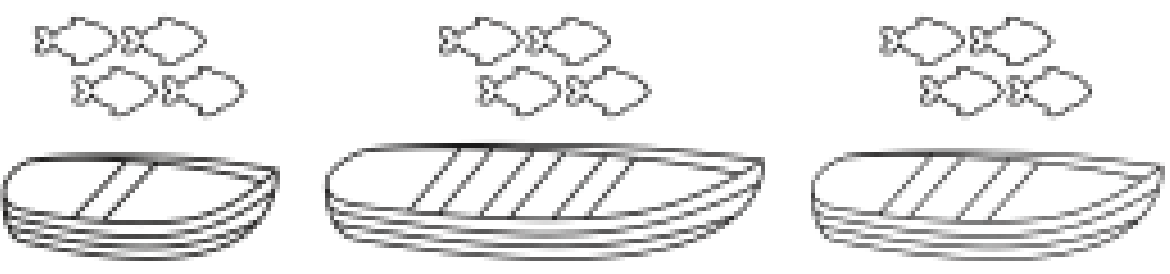

(b) Rolative aquity
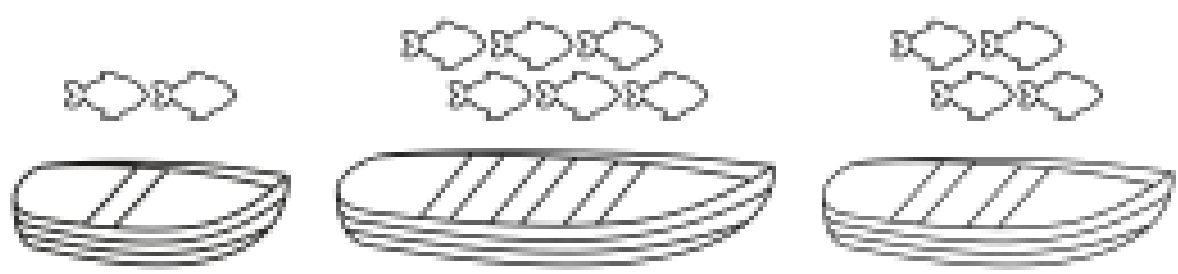

(c) Perceived equity
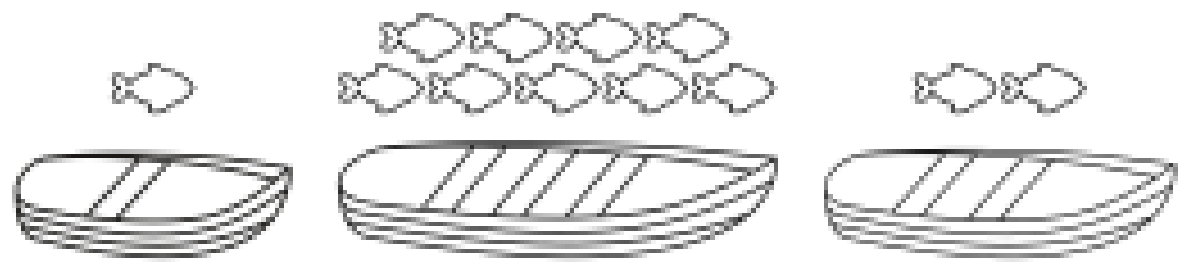

$453 \quad$ Figure 2 


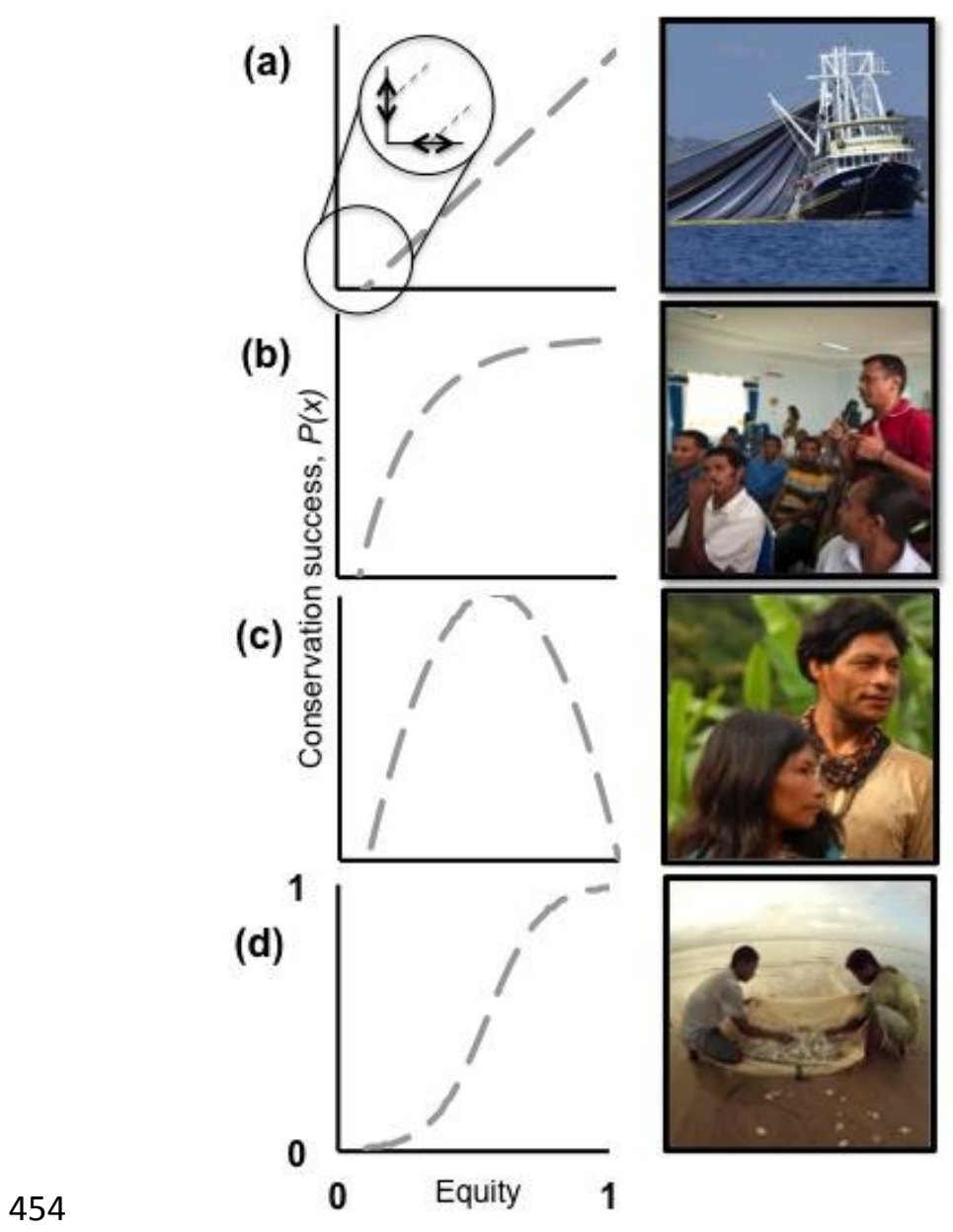

$455 \quad$ Figure 3 


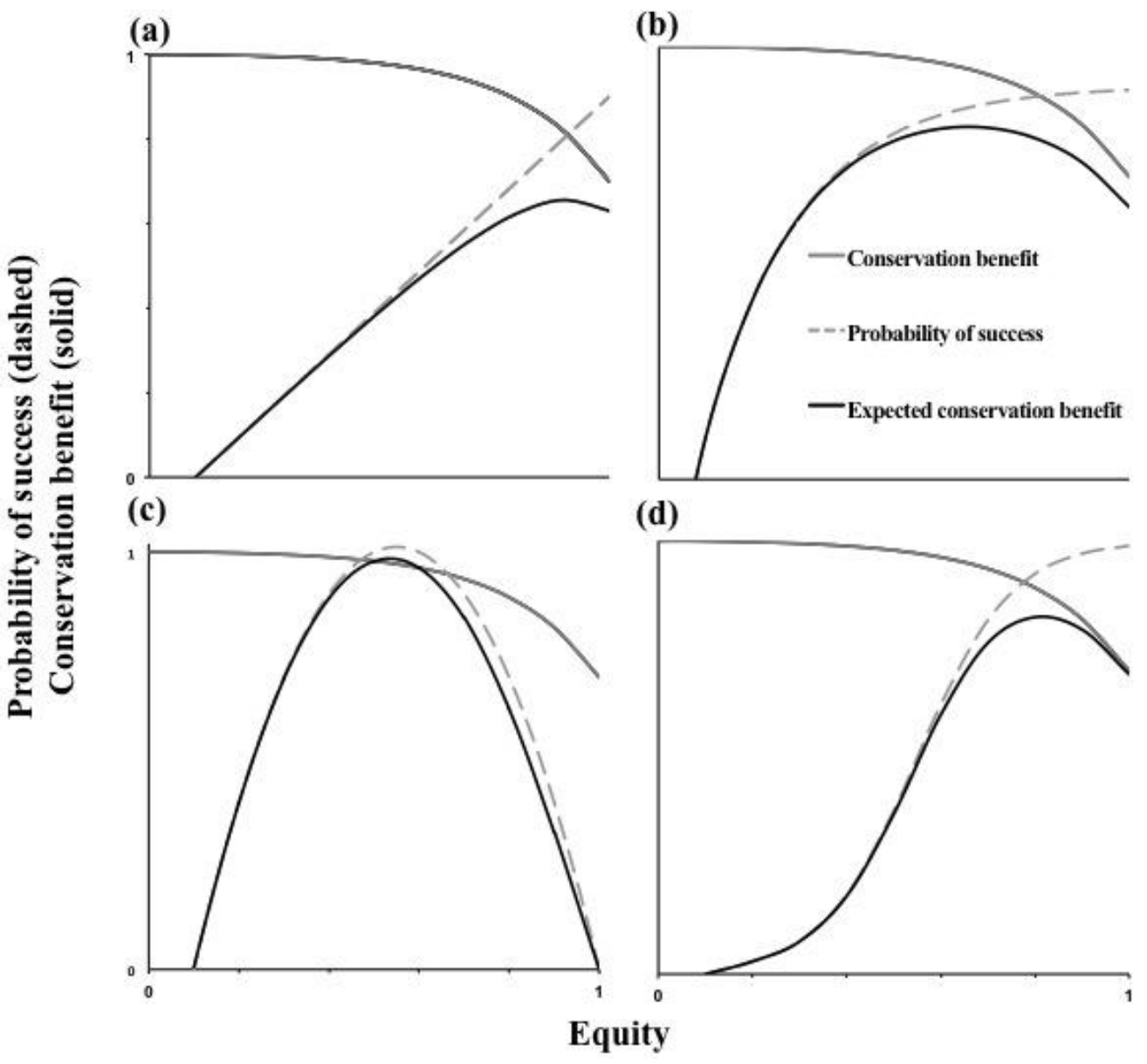

$457 \quad$ Figure 4 


\section{Figure Legends}

459 Figure 1. (a) Conservation success can be influenced by several different types of equity

460 (described in b), both as an input into (e.g., participation by stakeholder groups) and/or an 461 outcome of the conservation intervention (e.g., access to natural resources by individuals or 462 groups). Each type of equity can be influenced by a variety of socioeconomic and political 463 context determinants.

Figure 2. Equity influences conservation success in different ways, depending on how it is

466 measured and perceived. Potential measures and perceptions are illustrated for access equity, 467 where a management plan limits fishing access to different fisher groups (each with a different 468 size boat). When measured in absolute terms (a), each group benefits equally, represented by 469 catching the same number of fish; when measured in relative terms (b), the benefit is distributed 470 proportionally to the size of the boat. (c) the group with the largest boat has a positive 471 perception of the relative benefits, whereas groups with smaller boats have a negative 472 perception.

474 Figure 3. Four broad classes of relationship between equity and the probability of conservation 475 success, $P(x)$ : (a) Linear; (b) Asymptotic; (c) Humped; and (d) Sigmoidal. A value of 1 indicates 476 perfect equity and conservation success. For each relationship, we do not know where they cross 477 an axis (shown in (a)). If there is a minimum threshold of equity, below which there is zero 478 chance of success, then the lines would cross the x-axis; whereas if success is possible in 
479 inequitable situations, the lines would intercept the y-axis. Photos represent equity types that can

480 exhibit the associated relationship, occupational, participation, gender, and access, respectively.

481 Photos courtesy of (a) Urlich Karlowski; (b) World Wildlife Fund, Inc. Tory Read; (c) Trond

482 Larsen; (d) Cristina Mittermeier.

483 Figure 4. The relationship between equity and conservation benefit (i.e., success), and how

484 different relationships between probability of success ( $\mathrm{P}(\mathrm{x})$, from Fig. 3), given different levels

485 of equity modifies the ability of the conservation intervention to achieve biodiversity

486 conservation outcomes. The solid gray line shows a general possible trade-off between

487 conservation benefit and equity (taken from Halpern et al. 2013). The dashed gray lines show

488 four possible relationships between equity and probability of success, described in Figure 3 . The

489 solid black lines are the resulting consequence of these probability relationships on the degree to

490 which conservation success is achieved (expected conservation benefit). 


\section{Context (Governance, Policy, Values)}
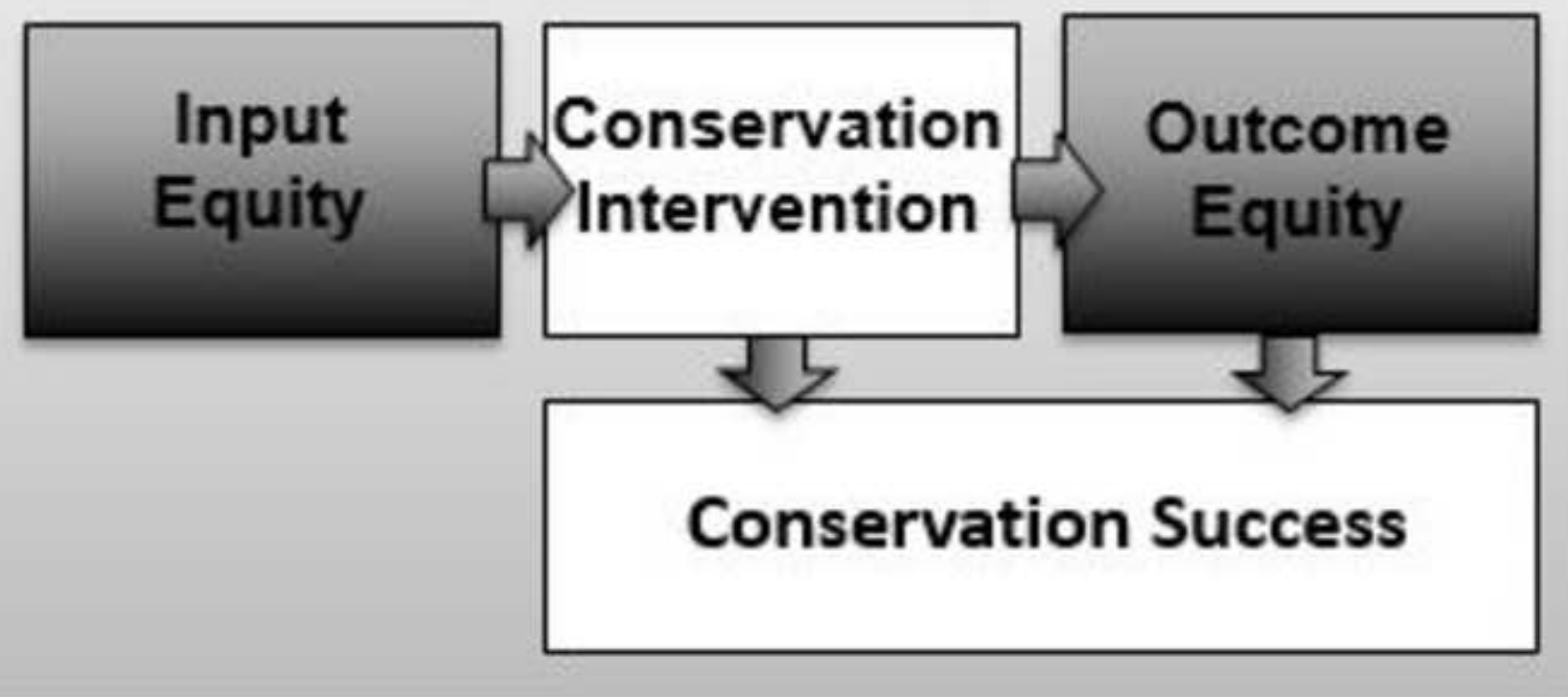


\section{Equity Type}

\section{Description}

Social class

Distribution of benefits or costs to each class, or people, according to set of hierarchical social categories

Distribution of benefits or costs to each

Gender gender group, where 50:50 ratio is perfect equity

\section{Distribution of benefits or costs to}

Ethnicity individuals or groups by cultural or indigenous status

Generational

Distribution of costs or benefits to each generation

Distribution of benefits or costs based

Educational upon level of education attainment (e.g., primary, secondary, tertiary)

Occupation

Distribution of benefits or costs to each occupational sector, where a sector could be individual types of fisheries (e.g., crab, tuna), different fishery groups (e.g., commercial, recreational), or different industries (e.g., wind farming, tourism) 


\section{Equity Metric}

\section{Description}

\section{Representation by type of}

Participation I stakeholder group in participatory conservation process of decision

Amount of non-spatial access allocated to individuals or groups,

Access

- such as access (or no access) to natural resources during a particular time period or season.

Amount of space or area on the

Spatial

- landscape/seascape allocated to individuals or groups

Financial

Amount of income or profitability allocated to individuals or groups 
Figure 2

Click here to download high resolution image

(a) Absolute equity
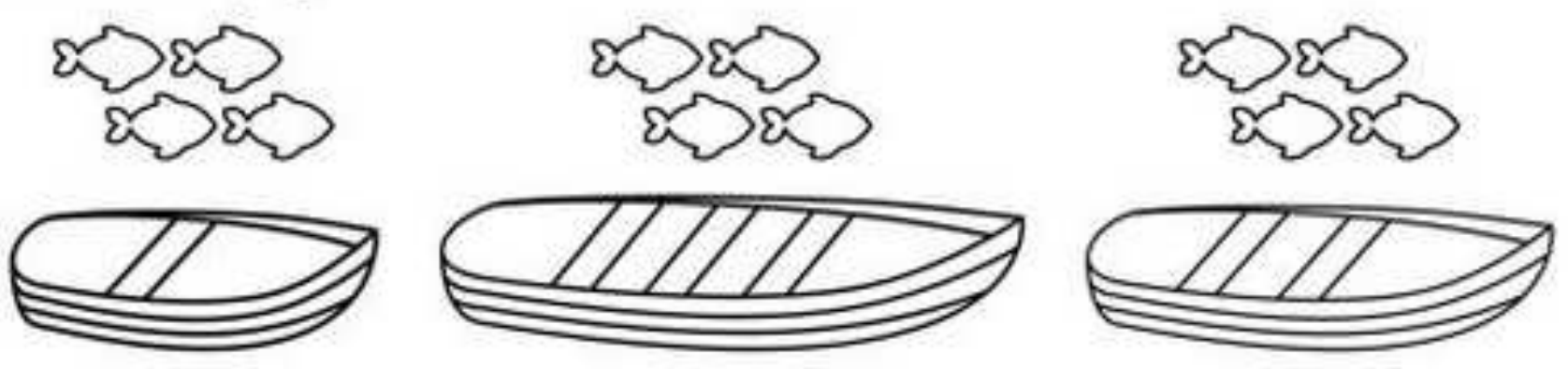

(b) Relative equity
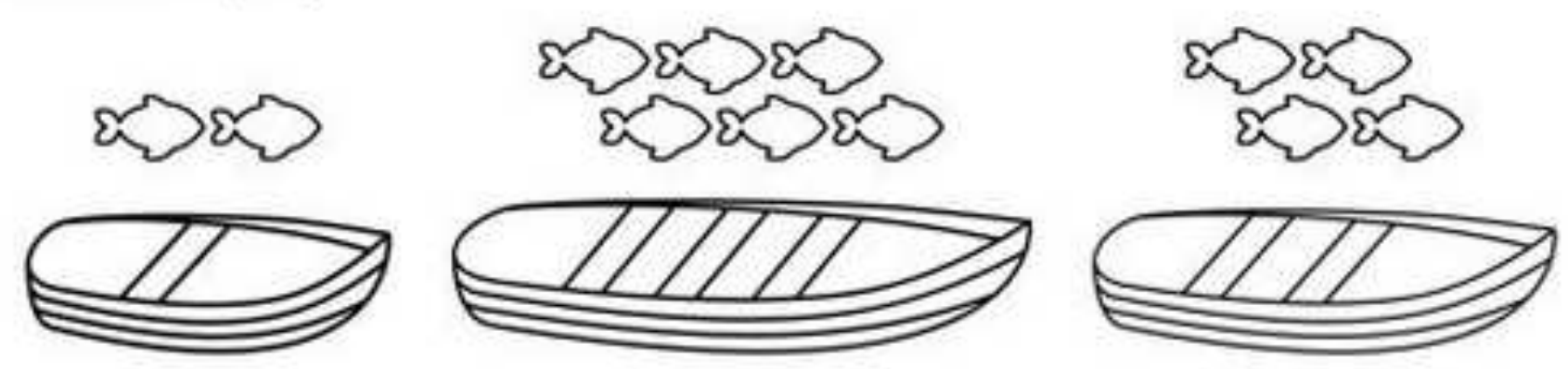

(c) Perceived equity
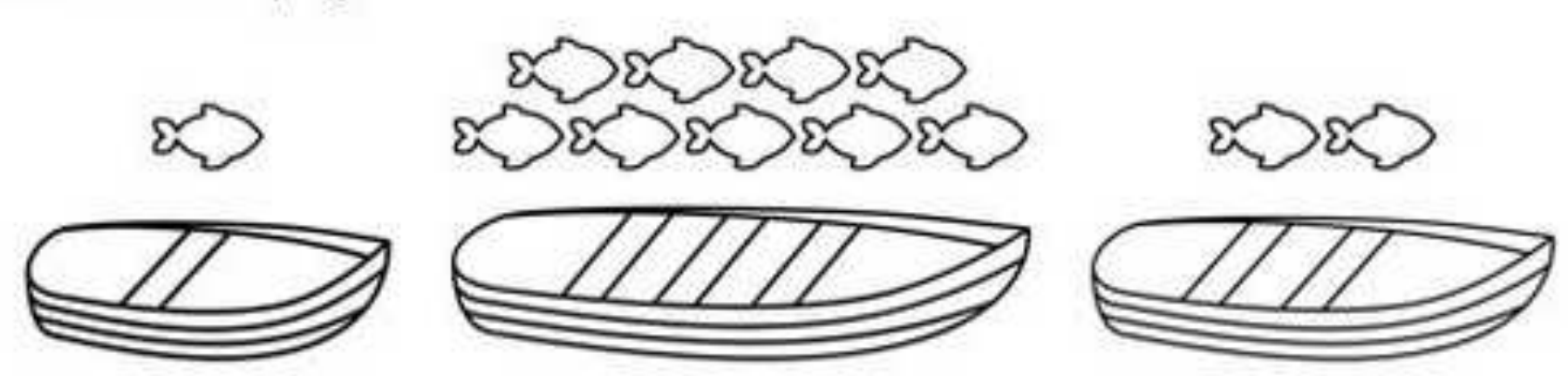
Click here to download high resolution image
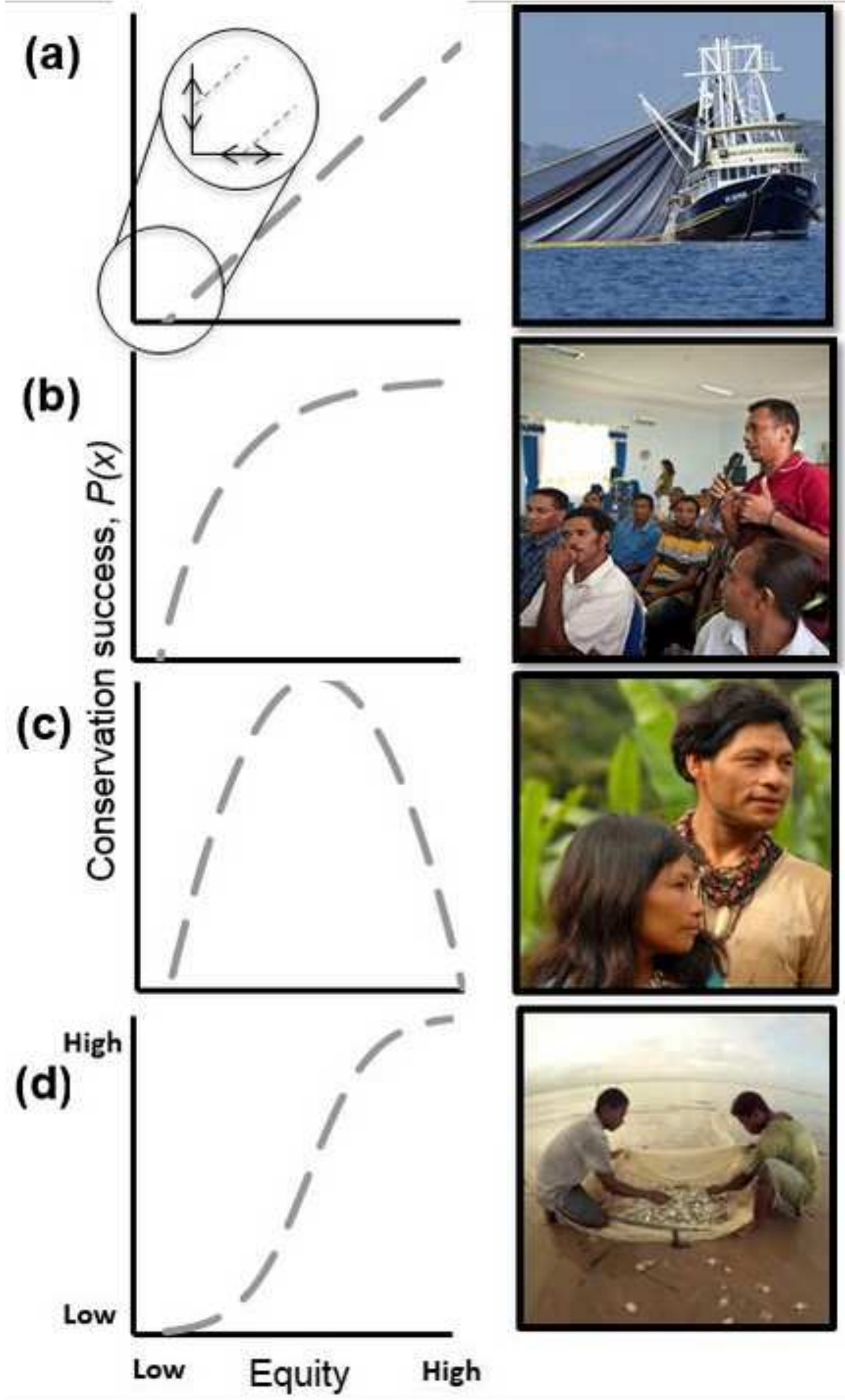

Low Equity High


(a)

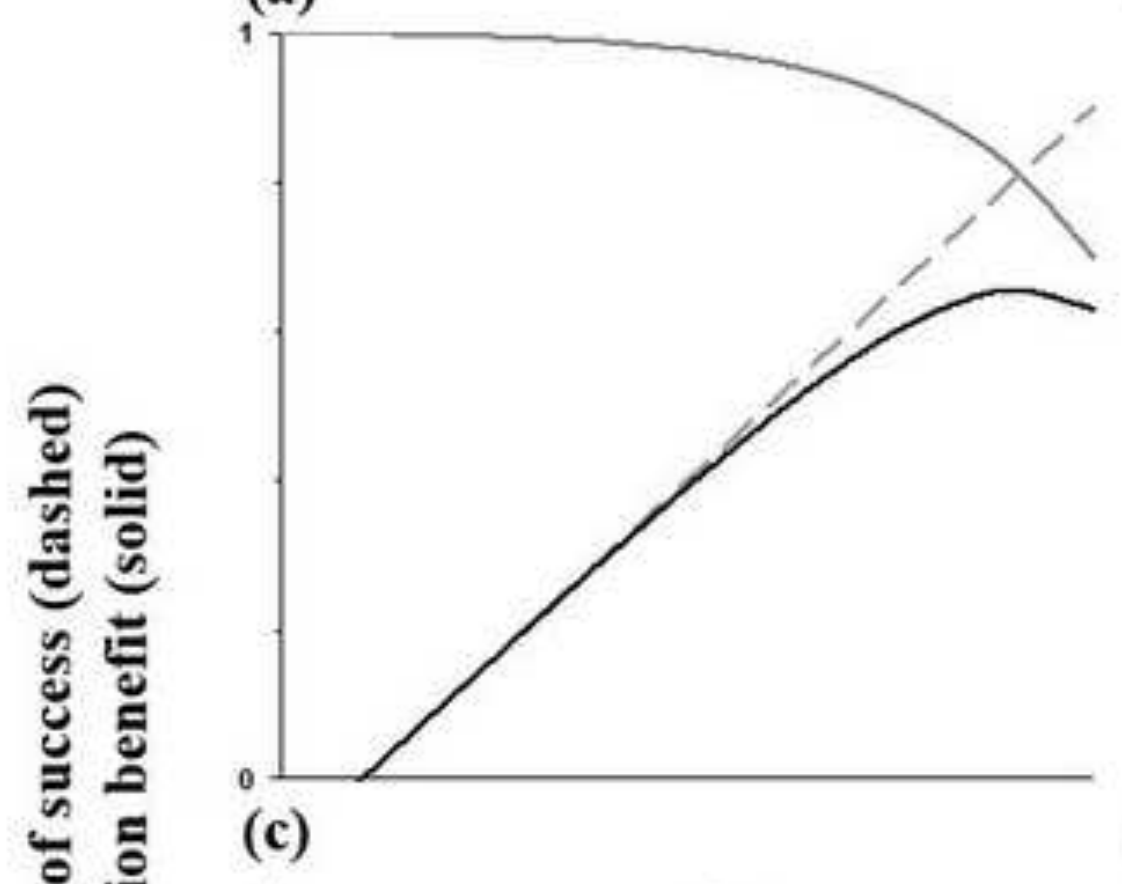

哀

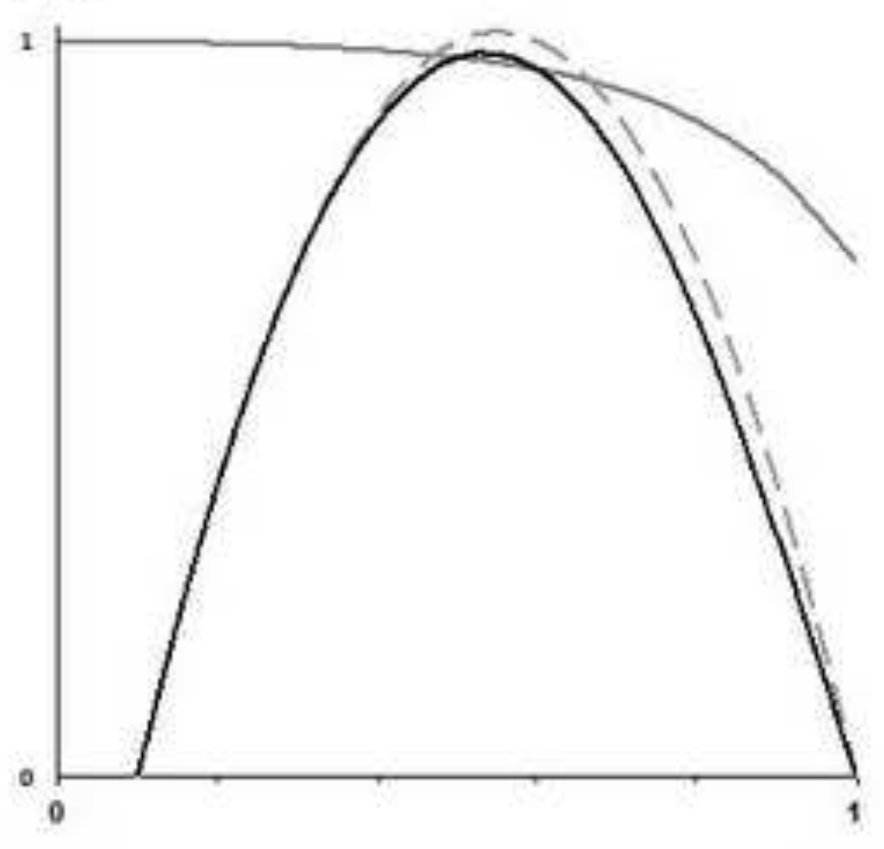

(b)

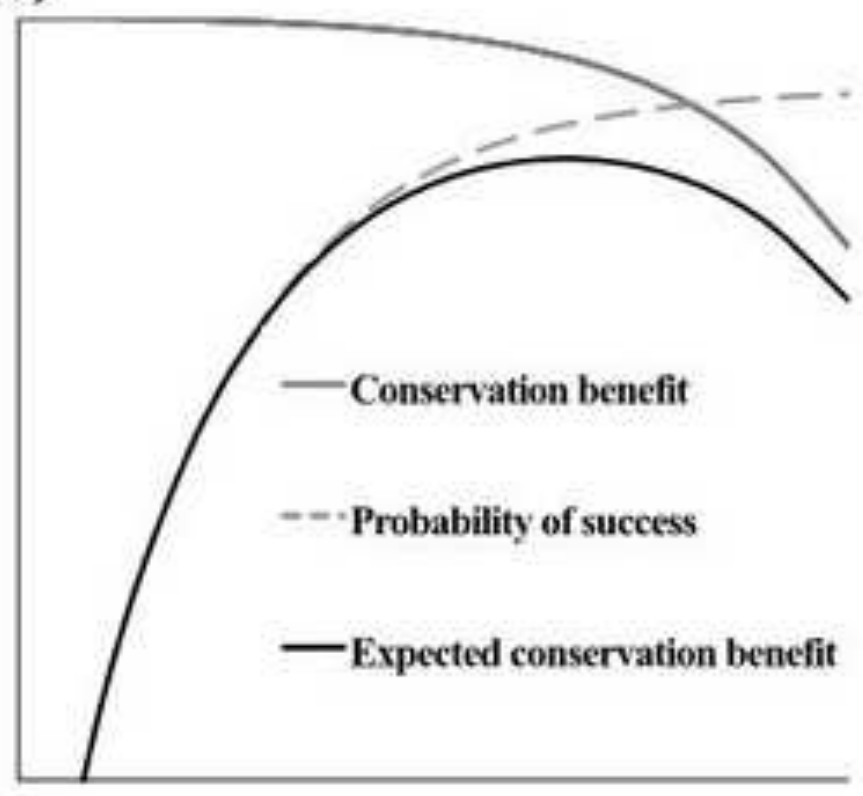

(d)

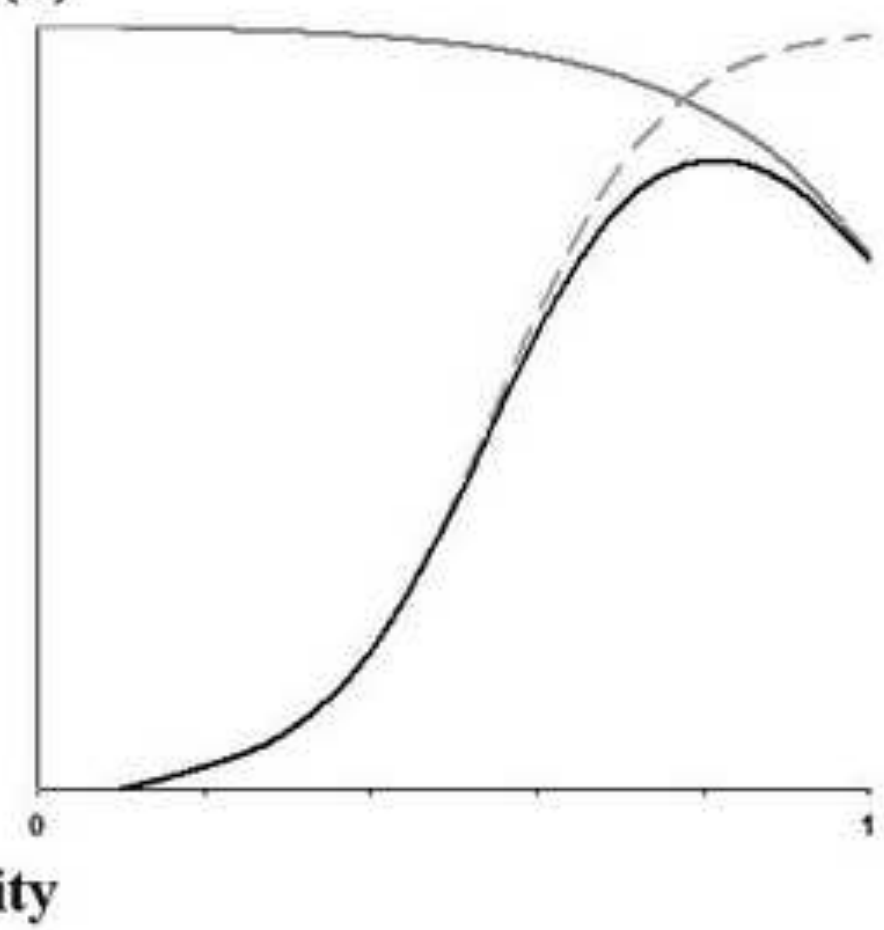

Equity 